\title{
Chronic Urinary Retention after Surgery for a Rare Case of Adult Presacral Teratoma
}

\author{
Funda Güngör Uğurlucan, Ahmet Cem İyibozkurt, Burçin Karamustafaoğlu, Betül Keyif, \\ Meryem Kürek Eken, Önay Yalçın
}

Department of Obstetrics and Gynecology, İstanbul University Faculty of Medicine, İstanbul, Turkey

Background: Presacral teratomas are usually observed in the first two decades of life and have a 50-67\% incidence of malignant transformation. Surgery is the treatment of choice.

Case Report: Here, we report the case of 24-year-old female with chronic urinary retention after surgery for a presacral teratoma.
Conclusion: Retroperitoneal pelvic surgery may cause pelvic plexus and nerve injury, leading to permanent bladder dysfunction and urinary retention. (Balkan Med J 2014;31:110-112).

Key Words: Presacral teratoma, retroperitoneal tumor, urinary retention
Teratomas are neoplasms made up of cells derived from all three germ layers. Retroperitoneal teratomas make up 1-11\% of primary retroperitoneal tumors, are very rarely encountered during adulthood and have a 50-67\% rate of malignant transformation (1). These neoplasms are usually asymptomatic, but may cause obstructive symptoms as the size increases. Surgical resection and histopathology are required for diagnosis and treatment.

Radical pelvic surgery may cause pelvic plexus and nerve injury and lead to bladder dysfunction and urinary retention with an incidence of $15-20 \%$ (2). Here, we report a case with chronic urinary retention after surgery for a rare case of adult presacral teratoma.

\section{CASE PRESENTATION}

A 24-year-old female presented with abdominal distention and pain. Abdominal/gynecologic examination and sonography revealed a mass measuring $18 \times 12 \times 12 \mathrm{~cm}$ posterior to the uterus. Magnetic resonance imaging showed a mass measuring $16 \times 18 \times 11 \mathrm{~cm}$, anterior to the rectosigmoid area suggestive of a teratoma with high-intensity signaling on T1-weighted images (Figure 1). There was no invasion of the adjacent structures, but bilateral mild hydronephrosis was observed. The uterus and the right ovary were normal, but the left ovary could not be visualized with magnetic resonance imaging probably due to the overlying mass. The tumor markers were normal.
The abdomen was entered through a midline incision. A 20 $\mathrm{cm}$ retroperitoneal mass anterior to the sacrum was observed. The ovaries and other abdominal structures were normal. The retroperitoneum was entered and the mass was dissected from the rectum and the sigmoid colon and the left ureter and was completely excised. The histopathology was mature cystic teratoma. The Foley catheter was removed on the postoperative third day, but spontaneous micturition was not possible. The Foley catheter was introduced again and bladder retraining with clamping the Foley catheter for three hours and draining the bladder every three hours was performed for 10 days, but spontaneous micturition was still not possible. Urinalysis, urine culture, and computed tomography scans were normal. Clean intermittent catheterization was taught and urodynamics were performed. The maximum bladder capacity was 750 $\mathrm{mL}$, and the first sensation of urine was at $748 \mathrm{~mL}$. The maximum detrusor pressure was $12 \mathrm{cmH}_{2} \mathrm{O}$. Electromyography of the external anal sphincter showed chronic denervation-reinnervation. The bulbocavernous reflex was normal. The patient continued clean intermittent catheterization for six months and urodynamics and pressure-flow studies were performed again six months later. The first sensation of urine was at 160 $\mathrm{mL}$. The maximum bladder capacity was $454 \mathrm{~mL}$. Compliance was $14 \mathrm{~mL} / \mathrm{cmH}_{2} \mathrm{O}$. Micturition was still not possible. The maximum detrusor pressure was $48 \mathrm{cmH}_{2} \mathrm{O}$. Informed consent was obtained from the patient and ethical consent was obtained from the local ethics committee for posterior tibial nerve stimulation (PTNS). PTNS was performed as 30-minute 


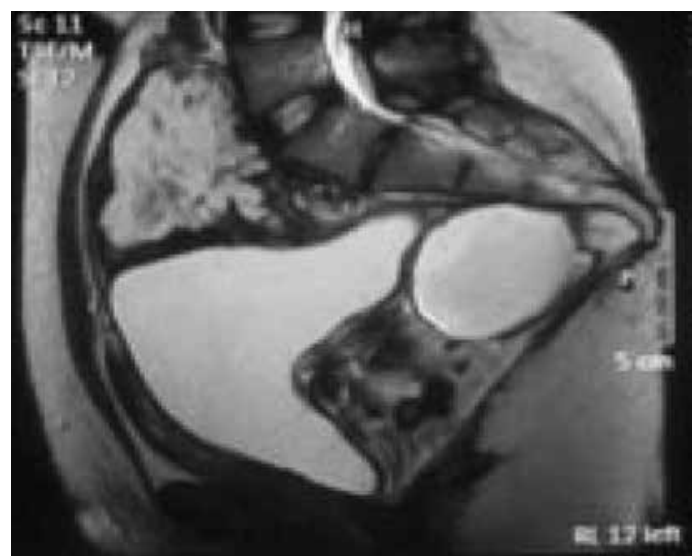

FIG. 1. Sagittal section of magnetic resonance imaging showing a retroperitoneal teratoma anterior to the sacrum

sessions each week for 12 weeks with Urgent PC neuromodulation system (Urgent ${ }^{\mathbb{P}}$ PC Neuromodulation System; Uroplasty, Minnetonka, USA), but no improvement was obtained. The patient was followed for 18 months after treatment. Clean intermittent catheterization was continued. In addition, the patient developed fecal impaction in the postoperative period, which was removed manually and stool softeners were ordered, but the patient had chronic constipation thereafter.

\section{DISCUSSION}

Teratomas are derived from all three germ layers and have various degrees of maturation classified as mature, immature, and malignant. Presacral teratomas are usually encountered in the first two decades of life (3). The risk of malignant transformation in early adulthood is $50-67 \%$ (4).

Most cases are asymptomatic, but in cases presenting with symptoms, those most commonly encountered include lower back and pelvic pain, constipation, and urinary retention due to the mass effect of the tumor and rarely from infiltration in the case of malignancy $(3,5)$. Our patient did not have any urinary complaints prior to surgery.

Magnetic resonance imaging is the diagnostic method of choice over other imaging modalities due to its superior soft tissue resolution, which is useful in determining the relationship to surrounding structures and the planes of resection (6). Differential diagnoses include mainly congenital abnormalities and tumors of the presacral area, neurogenic and osseous tumors and cysts, soft tissue tumors as well as uterine, ovarian and metastatic tumors.

Presacral teratomas are treated surgically. A posterior approach through a sacral incision, a transabdominal approach and a combined approach have been reported, depending on tumor size and location (3). The transabdominal approach is preferred for high lesions without evidence of sacral involvement. Recently, laparoscopic management has been reported as well (7).

Pelvic surgery for retroperitoneal tumors may cause pelvic plexus and nerve injury. Complete or partial transaction of the branches of the pelvic nerve, which arises from the hypogastric plexus may result in urinary retention with bladder hypotonia and areflexia (8). Treatment consists of clean intermittent catheterization and monitoring for the return of micturition. Cholinergic agonists may aid in the emptying of the bladder in selected cases. However, permanent micturition dysfunction may be observed in up to $25 \%$ of patients (2).

Sacral neuromodulation has been approved for the treatment of urinary urgency/frequency, urge incontinence, and non-obstructive urinary retention (2). The exact mechanism of action is not known but is believed to involve electrical modulation of the afferent and/or efferent nerves of the bladder. However, this is an invasive procedure with complications such as lead migration, mechanical failure and infection. Vandoninck et al. (9) reported 39 patients with chronic voiding dysfunction who were treated with PTNS. All of the patients had detrusor hypotonia, elevated residual urine volumes or complete urinary retention, and performed intermittent self-catheterization. PTNS was performed for 12 weeks at the medial malleolus in 30-min sessions. In $41 \%$ of the patients, the 24-hour catheterized volume was reduced by $50 \%$. An additional $26 \%$ of the patients had a $25-50 \%$ reduction in their residuals. Van Balken et al. (10), in their study, reported a decrease in the number and volume of catheterization in 12 patients with idiopathic urinary retention treated with PTNS. We used PTNS due to its minimally invasive nature with same principal of effect, but we could not obtain any improvement.

In conclusion, adult presacral teratomas are rare neoplasms treated with surgery. However, surgery may lead to pelvic nerve injury and chronic urinary retention unresponsive to neuromodulation. A multidisciplinary approach including general surgeons and neurosurgeons with nerve-sparing surgery is important for the prevention of this condition. Even then, this complication may be unavoidable.

Ethics Committee Approval: Ethics committee approval was received for this report from the local ethics committee.

Informed Consent: Written informed consent was obtained from patient who participated in this study.

Peer-review: Externally peer-reviewed.

Author contributions: Concept - F.G.U., B.K.; Design - B.K., M.K.E.; Supervision - A.C.İ., Ö.Y.; Resource - A.C.İ.; Materials - F.G.U., B.K.; Data Collection\&/or Processing - F.G.U.; Analysis\&/or Interpretation - F.G.U.; Literature Search - F.G.U., M.K.E.; Writing - F.G.U., B.K.; Critical Reviews - F.G.U.

Conflict of Interest: No conflict of interest was declared by the authors. 
Financial Disclosure: The authors declared that this study has received no financial support.

\section{REFERENCES}

1. Gatcombe HG, Assikis V, Kooby D, Johnstone P. Primary Retroperitoneal Teratomas: Review of the Literature. J Surgical Oncology 2004;86:107-13.[CrossRef]

2. Garg T, Machi G, Guralnick ML, O'Connor RC. Sacral Neuromodulation for Urinary Retention After Pelvic Plexus Injury. Urology 2007; 811: e11-e12.

3. Miles RM, Johnson JW Jr. Giant adult malignant sacrococcygeal teratoma: successful treatment by combined abdominosacral resection. $\mathrm{Am}$ Surg 1991;57:425-30.

4. Altman RP, Randolph JG, Lilly JR. Sacrococcygeal teratoma: Amer-ican Academy of Pediatrics Surgical Section Survey-1973. J Pediatr Surg 1974;9:389-98. [CrossRef]
5. Audet IM, Goldhahn RT Jr, Dent TL. Adult sacrococcygeal teratomas. Am Surg 2000;66:61-5.

6. Hassan I, Wietfeldt DE. Presacral Tumors: Diagnosis and Management. Clin Colon Rectal Surg 2009;22:84-93. [CrossRef]

7. Murdock J, Abbas MA. Laparoscopic Abdomino-paracocygeal resection of anorectal cystic teratoma. JSLS 2010;14:583-6. [CrossRef]

8. Hollabaugh RS, Steiner MS, Sellers KD, Samm BJ, Dmochowski RR. Neuroanatomy of the pelvis: implications for colonic and rectal resection. Dis Colon Rectum 2000;43:1390-7. [CrossRef]

9. Vandoninck V, van Balken MR, Finazzi Agrò E, Heesakkers JP, Debruyne FM, Kiemeney LA, et al. Posterior tibial nerve stimulation in the treatment of voiding dysfunction. Neurourol Urodyn 2004;23:246-51. [CrossRef]

10. Van Balken MR, Vandoninck V, Gisolf KW, Vergunst H, Kiemeney LA, Debruyne FM, et al. Posterior tibial nerve stimulation as neuromodulative treatment of lower urinary tract dysfunction. J Urol 2001;166:914-8. [CrossRef] 